University of Warwick institutional repository: http://go.warwick.ac.uk/wrap

This paper is made available online in accordance with publisher policies.

Please scroll down to view the document itself. Please refer to the repository record for this item and our policy information available from the repository home page for further information.

To see the final version of this paper please visit the publisher's website. Access to the published version may require a subscription.

Author(s): Kandala N-B, C Ji , N Stallard, S Stranges \& FP Cappuccio Article Title: Spatial Analysis of Risk Factors for Childhood Morbidity in Nigeria

Year of publication: 2007

Link to published version:

http://www.ajtmh.org/cgi/content/abstract/77/4/770 
Am. J. Trop. Med. Hyg., 77(4), 2007, pp. 770-778

Copyright (C) 2007 by The American Society of Tropical Medicine and Hygiene

\title{
Spatial Analysis of Risk Factors for Childhood Morbidity in Nigeria
}

\author{
Ngianga-Bakwin Kandala,* Chen Ji, Nigel Stallard, Saverio Stranges, and Francesco P. Cappuccio \\ Clinical Sciences Research Institute, Warwick Medical School, Coventry, United Kingdom; Health Sciences Research Institute, \\ Warwick Medical School, Coventry, United Kingdom
}

\begin{abstract}
Recent Demographic and Health Surveys (DHS) from Sub-Saharan Africa (SSA) indicate a decline in childhood vaccination coverage but a high prevalence of childhood diarrhea, cough, and fever. We used Nigerian DHS data to investigate the impact of geographical factors and other important risk factors on diarrhea, cough, and fever using geoadditive Bayesian semiparametric models. A higher prevalence of childhood diarrhea, cough, and fever is observed in the northern and eastern states, while lower disease prevalence is observed in the western and southern states. In addition, children from mothers with higher levels of education and those from poor households had a significantly lower association with diarrhea; children delivered in hospitals, living in urban areas, or from mothers having received prenatal visits had a significantly lower association with fever. Our maps are a novel and relevant tool to help local governments to improve health-care interventions and achieve Millennium Development Goals (MDG4).
\end{abstract}

\section{INTRODUCTION}

Childhood morbidity and mortality in Nigeria remain high in recent decades due to the burden associated with highly prevalent diseases such as diarrhea, malaria, and HIV/AIDS. In 2004, UNICEF statistics for Nigeria show an infant mortality rate of 101 per 1,000 live births, and 197 out of 1,000 children die under the age of 5 years. Few studies have investigated the association between diseases and socioeconomic, environmental, and individual risk factors in Nigeria and many other Sub-Saharan African (SSA) countries. ${ }^{1-5}$ The United Nations (UN) has set the Millennium Development Goals (MDG4) for all countries worldwide to reduce the rate of infant mortality in under-5s by two-thirds between 1990 and 2015.

Population surveys of health and fertility provide valuable insights into the etiology of diseases in developing countries. Moreover, they can provide nationally and regionally representative estimates on a range of epidemiologic variables. The Demographic and Health Surveys (DHS) are a well-established source of reliable population data with a substantial focus on childhood diseases and health-seeking behavior. However, linking individual survey records with disease prevalence at the disaggregated small-scale, community level has not been possible because of the methodological restraints of traditional regression modeling.

It is critical for policy makers to understand the prevalence of these diseases to plan proper health-care interventions at a community level. In a previous analysis, we examined the spatial location and childhood diseases for the Nigerian DHS 1999 and 2003 separately; in this report, we combine the 1999 and 2003 rounds of the Surveys to further investigate overall patterns of childhood epidemics in Nigeria.

Specifically, we apply the generalized geoadditive model $^{7}$ as an alternative to the common linear model, in the context of analyzing childhood disease in developing countries. This will enable us to account for nonlinear, location effects on childhood morbidity at the disaggregated district level (37 states) and to assess temporal and geographical variation in

\footnotetext{
* Address correspondence to Ngianga-Bakwin Kandala, Clifford Road Bridge, Clinical Sciences Research Institute, Warwick Medical School, Coventry CV2 2DX, United Kingdom. E-mail: N-B.kandala@ warwick.ac.uk
}

diseases while simultaneously controlling for important risk factors.

\section{METHODS}

Data source. The NDHS collects data on a nationally representative sample of women of child-bearing age (15-49 years) and their children. There were 3,552 children's records in the 1999 survey and 6,029 in 2003. Children under 3 years (35 months) were included in the 1999 survey, and children under 5 years (59 months) were in the 2003 survey. The NDHS samples are drawn through stratified clustered sampling with draws of 399 clusters in 37 states for the 1999 survey and 365 clusters in 37 states for the 2003 survey. The questionnaire includes information on socioeconomic indicators, fertility patterns, health and care practices, health knowledge, and anthropometric status for children born within the past 5 years. In this paper, the 1999 and $2003 \mathrm{Ni}$ gerian DHS data sets are pooled together to form 1 data set with the same socioeconomic, demographic, and health characteristics of the household. This is possible because the DHS surveys are carried out in a standardized form, with the same list of socioeconomic and demographic characteristics.

For the 2 surveys, data were collected on 9,581 children under the age of 5 years (59 months). By pooling the data from the 2 survey rounds, we were able to obtain a larger sample for each state, thus increasing the statistical power of our analyses. For the combined surveys, there were 8,189 observations for diarrhea, 8,152 for cough, and 8,165 for fever, representing $85.5 \%, 85.1 \%$, and $85.2 \%$ of the total survey sample.

In both surveys, health status was assessed by the answer to the question posed to the mother: "Has your child had diarrhea/cough/fever in the last two weeks?"

Most of the covariates were recategorized to be comparable to previous studies..$^{6,8,9,11}$ Poverty status is measured in the DHS surveys in terms of assets or wealth, rather than income or consumption. Ownership of consumer items, such as a radio or car, as well as characteristics of the dwelling, such as floor or roof type, toilet facilities, and water source, are items that measure the concept of poverty in these settings; this concept has been used by the World Bank to allocate households and thus their members into poverty quintiles, using principal components analysis (PCA) ${ }^{8}$ 
Statistical method. In the descriptive analysis, 2 pairs of frequency tables were generated to show the disease prevalence by district (states) and by factors. $\chi^{2}$ tests and MannWhitney tests were used to investigate the association between factors and diseases. Multivariate analysis shows the significance of the posterior mean estimates of fixed effects, nonlinear effects, and spatial effects. The model used in this study was a geoadditive semiparametric Bayesian model that contains a spatial effect. ${ }^{7,10,11}$ In this analysis, we apply a novel approach by exploring regional patterns of childhood morbidity and possible nonlinear effects of other factors within a simultaneous, coherent regression framework using a geoadditive semiparametric mixed model. The model used for this investigation has been described elsewhere. .,11,26 $^{2}$ Briefly, we replace the strictly linear predictor

$$
\eta_{i}=x^{\prime} \beta+w_{i}^{\prime} \gamma
$$

with a geoadditive predictor, leading to the geoadditive regression model:

$$
\eta_{i}=f_{1}\left(x_{i 1}\right)+\ldots+f_{\mathrm{p}}\left(x_{i \mathrm{p}}\right)+f_{\text {spat }}\left(s_{i}\right)+w_{i}^{\prime} \gamma
$$

where $f_{1}, \ldots, f_{\mathrm{p}}$ are nonlinear smooth effects of the metrical covariates (child's and mother's age), and $f_{\text {spat }}\left(s_{i}\right)$ is the effect of the spatial covariate $s_{i} \in\{1, \ldots, S\}$ labeling the districts (states) in Nigeria. Regression models with predictors as in (2) are sometimes referred to as geoadditive models. P-spline priors are assigned to the functions $f_{1}, \ldots, f_{\mathrm{p}}$ and for $f_{\mathrm{spat}}\left(s_{i}\right)$ we used Markov random field prior parameters. ${ }^{711,12,16,26}$

\section{RESULTS}

The observed prevalences of diarrhea, cough, and fever at district level by regions are presented in Table 1 and Figure 1. The country is divided into 6 regions (within 37 states) according to current political policy. The table also shows the relationships between diseases and districts or states by region.

The North East had the highest prevalence of childhood diarrhea $(30 \%)$. On average, children from states in the South West, South South, and South East were less associated with diarrhea than those living in the northern and central districts. All the states, except states in South East $(P=0.326)$, showed within-state variations of childhood diarrhea at $95 \%$ confidence level (all $P<0.01$ ).

The mean prevalence of childhood cough appeared to be higher than diarrhea across the country. Children from the North East and South South had the highest association with diseases $(31.6 \%$ and $32.5 \%$, respectively). The prevalence of childhood cough did not vary significantly across districts in the South East $(P=0.195)$. In all other regions, the prevalence of childhood cough varied significantly between districts (all $P<0.05$ ).

Childhood fever was more prevalent than diarrhea and cough. Four regions, the North West, North East, South South, and South East, showed $>30 \%$ of the children had had fever during the 2 weeks preceding the surveys. The prevalence of childhood fever did not significantly vary across states in the South East $(P=0.613)$. In all other regions, the prevalence of childhood fever varied significantly between districts (all $P<0.001)$.

Obviously, the observed prevalence fluctuated more at the district level than at the regional level. The regional classification masked the variations of morbidity in the states. For example, the lowest rate of diarrhea in the North Central area was $6.7 \%$ in Kwara State, whereas the highest was $27.5 \%$ in the federal capital, Abuja. This fact reveals that pronounced district variations were masked by regional classifications.

The distribution of all the factors we used in this analysis and their association with the diseases are shown in Table 2. The following factors were significantly associated with diarrhea: place of residence $(P<0.001)$; asset index $(P=0.009)$; antenatal visits $(P<0.001)$; place of delivery $(P<0.001)$; type of feeding $(P<0.001)$; mother's education $(P<0.001)$; and partner's education $(P<0.001)$. For cough, the significant factors were marital status $(P=0.005)$; antenatal visit $(P=$ $0.001)$; type of feeding $(P=0.005)$; mother's education $(P<$ $0.001)$; place of residence $(P=0.018)$; and partner's education $(P=0.002)$. For childhood fever, significant factors were place of residence $(P<0.001)$; place of delivery $(P<0.001)$; type of feeding $(P<0.001)$; mother's education $(P=0.001)$; and partner's education $(P=0.049)$.

Child's age appeared to be significantly associated with all diseases $(P<0.001, P=0.004$, and $P=0.002$ respectively). However, only mother's age had a significant association with childhood diarrhea $(P<0.001)$.

The left panel of Figure 2 presents the residual spatial district effects on the childhood diseases in Nigeria. Red represents a higher prevalence of childhood diseases, whereas green denotes a lower prevalence. A high prevalence of all 3 diseases was concentrated in the North and East of the country.

The right panel of Figure 2 shows the posterior probability maps of child morbidity at a $95 \%$ credible interval. The states in black indicated a significant positive spatial effect, whereas the states in white implied a significant negative spatial effect. The rest of the states (in gray) had no significant effect on the diseases. As represented by the maps, the northeastern part of the country had the highest association with childhood morbidity and the west-south-west and southeastern parts of the country the lowest.

The nonlinear effects of child's age and mother's age are shown in Figure 3 (left and right panel, respectively). Initially, the effect of child's age turned quickly from negative to positive for each disease as the child grew. Steeply rising curves at the beginning can be observed in all the graphs. During the first $8-10$ months, the effects on childhood cough and fever reached the highest point. The effect of age on diarrhea rose slightly after this period to the highest point. Afterward, the effect of child's age on all diseases decreased. At $\approx 35$ months, the confidence intervals widen, and by the end of the child's age category the intervals expand rapidly. Note that children $<35$ months were included in the 1999 survey whereas children $<59$ months were included in 2003. Thus the large intervals are caused by fewer observations after 35 months involved in the data set.

Mother's age shows different effects on the 3 diseases. The large confidence intervals at the beginning and the end of the curves suggest unreliable estimations of the effect of mother's age. Moreover, compared with child's age, the effect of mother's age is more linearly related to child morbidity, suggesting a nonsignificant nonlinear association with disease.

Table 3 shows the fixed effects of categorical covariates after controlling for spatial dependence in the data. Several 
TABLE 1

Observed diarrhoea, cough, and fever prevalence by districts of Nigeria (DHS 1999 and 2003)*

\begin{tabular}{|c|c|c|c|c|c|c|c|c|c|c|}
\hline \multirow[b]{2}{*}{ Region } & \multirow[b]{2}{*}{ State } & \multicolumn{3}{|c|}{ Diarrhoea recently (\% and $N$ ) } & \multicolumn{3}{|c|}{ Cough recently $(\%$ and $N$ ) } & \multicolumn{3}{|c|}{ Fever recently (\% and $N$ ) } \\
\hline & & No & Yes & $P$ values & No & Yes & $P$ values & No & Yes & $P$ values \\
\hline \multirow[t]{8}{*}{ North West } & Kaduna & 85.9 (413) & $14.1(68)$ & & $82.2(393)$ & $17.8(85)$ & & $60(289)$ & $40(193)$ & \\
\hline & Kano & $78.4(480)$ & $21.6(132)$ & & $81.7(500)$ & $18.3(112)$ & & $57.7(353)$ & $42.3(259)$ & \\
\hline & Katsina & 80 (178) & $20(87)$ & & $87(376)$ & $13(56)$ & & $72.7(315)$ & $27.3(118)$ & \\
\hline & Sokoto & 87.7 (349) & $12.3(25)$ & & $84.2(171)$ & $15.8(32)$ & & 77.8 (158) & $22.2(45)$ & \\
\hline & Jigawa & 78 (181) & $22(51)$ & & 82.7 (191) & $17.3(40)$ & & $67.1(155)$ & $32.9(76)$ & \\
\hline & Kebbi & 80.7 (176) & $19.3(42)$ & & 81.5 (176) & $18.5(40)$ & & 65.7 (142) & $34.3(74)$ & \\
\hline & Zamfara & $77.5(200)$ & $22.5(58)$ & & 72.4 (184) & $27.6(70)$ & & $60.2(154)$ & 39.8 (102) & \\
\hline & Total & 81 (1977) & $19(463)$ & 0.003 & $82.1(1991)$ & $17.9(435)$ & 0.001 & $64.4(1566)$ & $35.6(867)$ & 0.000 \\
\hline \multirow[t]{7}{*}{ North East } & Bauchi & $67.9(383)$ & $32.1(181)$ & & $70.5(397)$ & $29.5(166)$ & & $63.3(356)$ & $36.7(206)$ & \\
\hline & Borno & 65.9 (184) & $34.1(95)$ & & $68.2(191)$ & $31.8(89)$ & & $73.4(204)$ & $26.6(74)$ & \\
\hline & Adamawa & 64.3 (119) & $35.7(66)$ & & $51.6(95)$ & $48.4(89)$ & & $50(92)$ & $50(92)$ & \\
\hline & Taraba & $73.4(160)$ & $26.6(58)$ & & $71(154)$ & $29(63)$ & & 59.1 (127) & $40.9(88)$ & \\
\hline & Yobe & $76.2(182)$ & $23.8(57)$ & & 68.9 (164) & $31.1(74)$ & & $62(147)$ & $38(90)$ & \\
\hline & Gombe & 77 (127) & $23(38)$ & & 76.5 (127) & $23.5(39)$ & & 69.9 (116) & $30.1(50)$ & \\
\hline & Total & $70(1155)$ & $30(495)$ & 0.008 & $68.4(1128)$ & $31.6(520)$ & 0.000 & $63.5(1042)$ & $36.5(600)$ & 0.000 \\
\hline \multirow[t]{8}{*}{ North Central } & Benue & $87.5(294)$ & $12.5(42)$ & & $70.3(234)$ & $29.7(99)$ & & $79.3(264)$ & $20.7(69)$ & \\
\hline & Kwara & $93.3(140)$ & $6.7(10)$ & & 84 (126) & $16(24)$ & & $82(123)$ & $18(27)$ & \\
\hline & Niger & $84.1(232)$ & $15.9(44)$ & & 86.8 (236) & $13.2(36)$ & & 80.5 (219) & $19.5(53)$ & \\
\hline & Plateau & $74.8(172)$ & $25.2(58)$ & & $70(161)$ & $30(69)$ & & $62.2(143)$ & $37.8(87)$ & \\
\hline & Kogi & 91.3 (189) & 8.7 (18) & & 89.9 (186) & $10.1(21)$ & & $83.6(173)$ & $16.4(34)$ & \\
\hline & Nassarawa & $86.2(94)$ & $13.8(15)$ & & $76.1(83)$ & $23.9(26)$ & & $69.7(76)$ & $30.3(33)$ & \\
\hline & F.C.T. (Abuja) & $72.5(50)$ & 27.5 (19) & & $70.6(48)$ & $29.4(20)$ & & $63.2(43)$ & $36.8(25)$ & \\
\hline & Total & $85(1171)$ & $15(206)$ & 0.000 & $78.5(1074)$ & $21.5(295)$ & 0.000 & $76(1041)$ & $24(328)$ & 0.000 \\
\hline \multirow[t]{7}{*}{ South West } & Lagos & $95.8(321)$ & $4.2(14)$ & & $77.2(258)$ & $22.8(76)$ & & $84.2(283)$ & $15.8(53)$ & \\
\hline & Ogun & $88.3(188)$ & $11.7(25)$ & & $85.3(180)$ & $14.7(31)$ & & $83.7(175)$ & $16.3(34)$ & \\
\hline & Ondo & $86.9(93)$ & $13.1(14)$ & & $77.6(83)$ & $22.4(24)$ & & $65.1(69)$ & $34.9(37)$ & \\
\hline & Oyo & $94.6(212)$ & $5.4(12)$ & & 87.1 (195) & $12.9(29)$ & & 73.1 (166) & $26.9(61)$ & \\
\hline & Osun & 94.1 (111) & $5.9(7)$ & & $86.4(102)$ & $13.6(16)$ & & $83.8(98)$ & $16.2(19)$ & \\
\hline & Ekiti & $96.7(59)$ & $3.3(2)$ & & $83.6(51)$ & $16.4(10)$ & & $82(50)$ & $18(11)$ & \\
\hline & Total & $93(984)$ & $7(74)$ & 0.002 & $82.4(869)$ & $17.6(186)$ & 0.017 & $79.6(841)$ & $20.4(215)$ & 0.000 \\
\hline \multirow[t]{7}{*}{ South South } & Akwa Ibom & $85.6(208)$ & $14.4(35)$ & & 65.7 (159) & $34.3(83)$ & & $55.5(136)$ & $44.5(109)$ & \\
\hline & Edo & $96.4(134)$ & $3.6(5)$ & & $73.5(100)$ & $26.5(36)$ & & $74.6(103)$ & $25.4(35)$ & \\
\hline & Cross River & 87.6 (106) & $12.4(15)$ & & $57.9(70)$ & $42.1(51)$ & & $59.5(72)$ & $40.5(49)$ & \\
\hline & Rivers & 89.8 (158) & $10.2(18)$ & & $72.8(126)$ & $27.2(47)$ & & $65.3(115)$ & $34.7(61)$ & \\
\hline & Delta & 89.9 (179) & $10.1(20)$ & & $68.3(136)$ & $31.7(63)$ & & 74.4 (148) & $25.6(51)$ & \\
\hline & Bayelsa & $82.4(42)$ & $17.6(9)$ & & $60.8(31)$ & $39.2(20)$ & & $54.9(28)$ & $45.1(23)$ & \\
\hline & Total & 89 (827) & $11(102)$ & 0.009 & $67.5(622)$ & $32.5(300)$ & 0.05 & $64.7(602)$ & $35.3(328)$ & 0.000 \\
\hline \multirow[t]{6}{*}{ South East } & Anambra & 88 (147) & $12(20)$ & & $72.3(120)$ & $27.7(46)$ & & 71.1 (118) & $28.9(48)$ & \\
\hline & Imo & 91.8 (146) & $8.2(13)$ & & 66.7 (106) & $33.3(53)$ & & $66(105)$ & $34(54)$ & \\
\hline & Abia & $89.5(102)$ & $10.5(12)$ & & $79.5(89)$ & $20.5(23)$ & & $69.3(79)$ & $30.7(35)$ & \\
\hline & Enugu & 84.8 (128) & $15.2(23)$ & & 69.7 (106) & $30.3(46)$ & & $63.2(96)$ & $36.8(56)$ & \\
\hline & Ebonyi & 91 (131) & $9(13)$ & & 74.1 (106) & $25.9(37)$ & & $66(95)$ & $34(49)$ & \\
\hline & Total & $89(654)$ & $11(81)$ & 0.326 & $72(527)$ & $28(205)$ & 0.195 & $67.1(493)$ & $32.9(242)$ & 0.613 \\
\hline All & & $82.6(6768)$ & $17.4(1421)$ & & $76.2(6211)$ & 23.8 (1941) & & $68.4(5585)$ & $31.6(2580)$ & \\
\hline
\end{tabular}

* Confidence Level: $95 \%$.

factors were significantly associated with childhood morbidity. The overall effect of each factor is indicated by the posterior mean. Children from educated mothers have a lower association with childhood diarrhea. The upper quintiles of the asset index, which represents children in families in the group of highest household economic status, did not have preventative effects on diarrhea. Additionally, urbanized areas have a lower association with childhood fever. Children of mothers who had prenatal visits and delivered in a hospital were less likely to get fever. However, if mothers fed children with mixed foods (breast milk, water, fruit juice, or other solid foods) or the preceding birth interval was at least 2 years (> 25 months), then the association with childhood fever significantly increased. Unexpectedly, there is no factor showing any significant association with childhood cough.

\section{DISCUSSION}

After controlling for covariates, the residual spatial effects identifies a clear and strong spatial structure at the district level in Nigeria, which shows that a higher prevalence of childhood morbidity appears mainly in the north-eastern states and a lower prevalence is present in the south-western states. The covariates are also able to explain part of the spatial structure, although a large amount of unexplained residual spatial effects remain.

We carried out a sensitivity analysis about different prior assumptions for spatial effects. It turned out that Markov random field (MRF) prior parameters outperformed the other prior parameters. ${ }^{17}$ The result is in line with the findings of a previous analysis using other survey data. ${ }^{6}$ There are vari- 


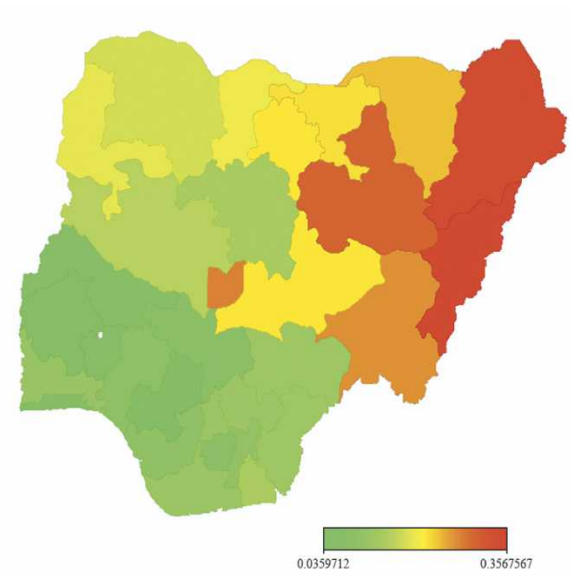

Diarrhea

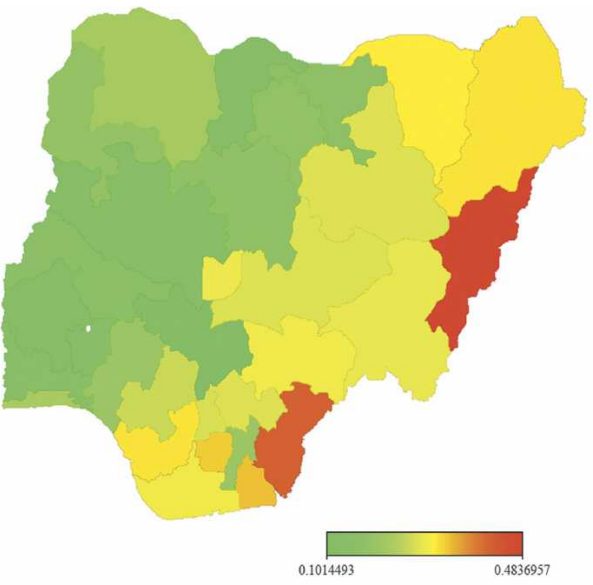

Cough

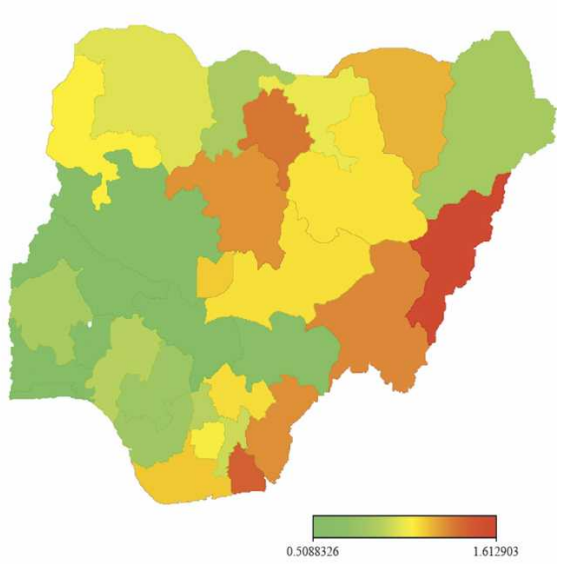

Fever

FigurE 1. Observed disease prevalence for diarrhea (left), cough (middle), and fever (right) by states (DHS, 1999-2003). This figure appears in color at www.ajtmh.org.

TABLE 2

Distribution of factors analyzed in childhood morbidity study in Nigeria (DHS 1999 and 2003)*

\begin{tabular}{|c|c|c|c|c|c|c|c|c|c|}
\hline & \multicolumn{3}{|c|}{ Diarrhoea recently (\% and $N$ ) } & \multicolumn{3}{|c|}{ Cough recently (\% and $N$ ) } & \multicolumn{3}{|c|}{ Fever recently (\% and $N$ ) } \\
\hline & No & Yes & $P$ values & No & Yes & $P$ values & No & Yes & $P$ values \\
\hline \multicolumn{10}{|l|}{ Sex of child } \\
\hline Male & $82.1(3408)$ & $17.9(744)$ & \multirow[t]{2}{*}{0.170} & $76.1(3147)$ & $23.9(990)$ & \multirow[t]{2}{*}{0.815} & $67.7(2801)$ & $32.2(1337)$ & \multirow[t]{2}{*}{0.167} \\
\hline Female & $83.2(3360)$ & $16.8(677)$ & & $76.3(3064)$ & $23.7(951)$ & & $69.1(2784)$ & $30.9(1243)$ & \\
\hline \multicolumn{10}{|l|}{ Preceding birth interval } \\
\hline$<25$ months & 83.4 (1329) & $16.6(264)$ & \multirow[t]{2}{*}{0.142} & $76.2(1205)$ & $23.8(377)$ & \multirow[t]{2}{*}{0.609} & 68.7 (1091) & $31.3(496)$ & \multirow{2}{*}{0.642} \\
\hline $25+$ months & 81.8 (4049) & $18.2(902)$ & & $76.8(3789)$ & $23.2(1145)$ & & $68.1(3361)$ & $31.9(1575)$ & \\
\hline \multicolumn{10}{|l|}{ Place of residence } \\
\hline Urban & $85.1(2365)$ & $14.9(415)$ & \multirow[t]{2}{*}{0.000} & $77.8(2153)$ & $22.2(616)$ & \multirow[t]{2}{*}{0.018} & $72.3(2008)$ & $27.7(768)$ & \multirow[t]{2}{*}{0.000} \\
\hline Rural & $81.4(4403)$ & $18.6(1006)$ & & $75.4(4058)$ & $24.6(1325)$ & & $66.4(3577)$ & $33.6(1812)$ & \\
\hline \multicolumn{10}{|l|}{ Marital status } \\
\hline Single & $81.9(295)$ & $18.1(65)$ & \multirow[t]{2}{*}{0.722} & $69.8(247)$ & $30.2(107)$ & \multirow[t]{2}{*}{0.005} & $64(228)$ & $36(128)$ & \multirow[t]{2}{*}{0.080} \\
\hline Married & 82.7 (6473) & $17.3(1356)$ & & $76.5(5964)$ & $23.5(1834)$ & & $68.6(5357)$ & $31.4(2452)$ & \\
\hline \multicolumn{10}{|l|}{ Asset index } \\
\hline 1st quantile & 79.5 (1077) & $20.5(277)$ & \multirow[t]{4}{*}{0.009} & $76.4(1026)$ & $23.6(317)$ & \multirow[t]{4}{*}{0.169} & $67.9(915)$ & $32.1(433)$ & 0.709 \\
\hline 2nd quantile & 82.8 (1922) & $17.2(398)$ & & $77.6(1794)$ & 22.4 (519) & & 67.9 (1574) & $32.1(744)$ & \\
\hline 3rd quantile & 83.7 (2427) & $16.3(471)$ & & $75.4(2178)$ & $24.6(709)$ & & $68.5(1978)$ & $31.5(910)$ & \\
\hline 4th quantile & $82.5(1130)$ & $17.5(239)$ & & 74.7 (1019) & $25.3(346)$ & & $69.6(951)$ & $30.4(415)$ & \\
\hline Household size & & & & & & & & & \\
\hline Small household & $84.5(49)$ & $15.5(9)$ & 0.724 & $76.8(43)$ & $23.2(13)$ & 0.590 & $63.2(36)$ & $36.8(21)$ & 0.592 \\
\hline Medium household & $83(2528)$ & $17(517)$ & & $75.6(2291)$ & $24.4(741)$ & & $68.1(2065)$ & $31.9(969)$ & \\
\hline Large household & 82.4 (4191) & $17.6(895)$ & & $76.6(3877)$ & 23.4 (1187) & & $68.7(3484)$ & $31.3(1590)$ & \\
\hline Antenatal visit & & & & & & & & & \\
\hline Have some visits & $82.6(3381)$ & $17.4(713)$ & 0.000 & $73.3(2991)$ & $26.7(1090)$ & 0.001 & $66.4(2718)$ & $33.6(1377)$ & 0.422 \\
\hline No & 76.2 (1549) & $23.8(484)$ & & $77.2(1564)$ & $22.8(462)$ & & $65.3(1326)$ & $34.7(704)$ & \\
\hline delivery & & & & & & & & & \\
\hline Hospital & $87.9(2711)$ & $12.1(374)$ & 0.000 & $76.1(2339)$ & $23.9(734)$ & 0.851 & $73.1(2252)$ & $26.9(828)$ & 0.000 \\
\hline Homes and others & 79.5 (4043) & $20.5(1045)$ & & $76.3(3863)$ & $23.7(1200)$ & & $65.5(3321)$ & 34.5 (1747) & \\
\hline Feedtype & & & & & & & & & \\
\hline Exclusive breastfeeding & $88.5(276)$ & $11.5(36)$ & 0.000 & $83.5(258)$ & $16.5(51)$ & 0.005 & $76.8(239)$ & $23.3(72)$ & 0.000 \\
\hline No breastfeeding & $83.5(2510)$ & $16.5(495)$ & & $75.5(2254)$ & $24.5(733)$ & & $68.3(2046)$ & $31.7(948)$ & \\
\hline Mixed feeding & $80.6(2968)$ & $19.4(716)$ & & $75.3(2764)$ & $24.7(909)$ & & $65.7(2414)$ & $34.3(1259)$ & \\
\hline Mother's education & & & & & & & & & \\
\hline Yes & $86.4(3670)$ & $13.6(576)$ & 0.000 & $74.5(3146)$ & $25.5(1075)$ & 0.000 & $70.1(2968)$ & $29.9(1265)$ & 0.001 \\
\hline No & $78.6(3098)$ & $21.4(845)$ & & $78(3065)$ & $22(866)$ & & $66.6(2617)$ & $33.4(1315)$ & \\
\hline Partner's education & & & & & & & & & \\
\hline Yes & 84.7 (4159) & $15.3(751)$ & 0.000 & $75.1(3673)$ & $24.9(1215)$ & 0.002 & $69.2(3389)$ & $30.8(1510)$ & 0.049 \\
\hline No & 79.3 (2394) & $20.7(625)$ & & $78.1(2351)$ & $21.9(658)$ & & $67.1(2017)$ & $32.9(991)$ & \\
\hline Type of toilet facilities & & & & & & & & & \\
\hline Pit or flush toilet & & & & & & & & & \\
\hline facilities & $82.2(4892)$ & $17.8(1058)$ & 0.120 & $76(4500)$ & $24(1421)$ & 0.365 & $68.1(4040)$ & $31.9(1895)$ & 0.320 \\
\hline No facility & 83.7 (1711) & $16.3(332)$ & & 77 (1569) & $23(468)$ & & $69.3(1410)$ & $30.7(625)$ & \\
\hline Child's age in months & $28.54(6.81)$ & $27.84(6.88)$ & 0.000 & $28.48(6.81)$ & $28.28(6.95)$ & 0.004 & $28.5(6.81)$ & $28.27(6.89)$ & 0.002 \\
\hline Mother's age & $23.19(16.15)$ & $20.38(12.95)$ & 0.000 & $23.07(16.04)$ & 21.48 (14.47) & 0.158 & $23.21(16.28)$ & $21.51(14.22)$ & 0.158 \\
\hline
\end{tabular}



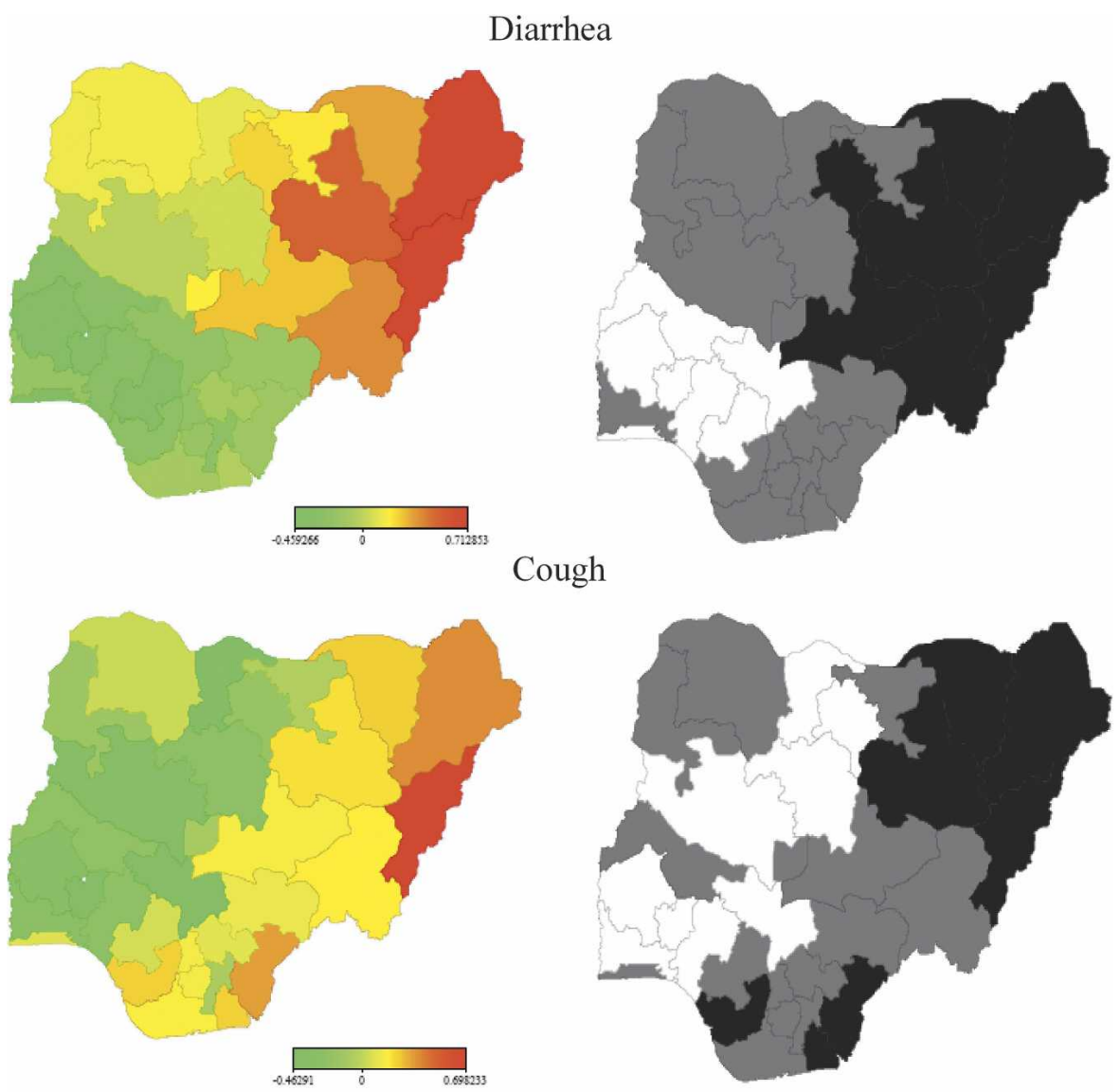

Fever
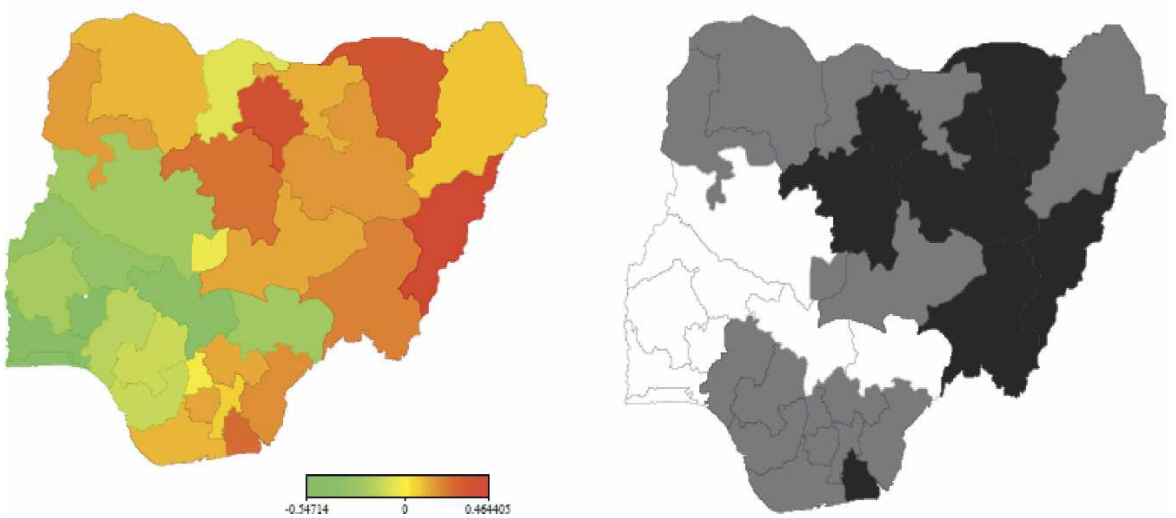

Figure 2. Residual spatial districts effects (left) and $95 \%$ posterior probability map (right) of child morbidity in Nigeria. This figure appears in color at www.ajtmh.org.

ous reasons for the higher associations with disease in the northern and eastern states. Sahelian drought is probably one of the most influential reasons. In recent studies, ${ }^{19,20}$ it has been found to be an important, socioeconomic determinant in both northern Nigeria and neighboring countries, which have suffered from increasing pressures on the available resources due to a fluctuating rainfall regimen in the latter part of the last century. Therefore, agricultural activities have been severely affected, and the resulting food security crisis forced people to consume unfit food and polluted water, which in turn affected feeding practices. Meanwhile, the resulting poverty prevents people from accessing the free health centers and buying medication. On the other hand, the higher asso- ciation with childhood cough and fever, observed in several southern states, are probably linked to oil spillages and environmental pollution. ${ }^{2,21}$ In the 1950 s, the discovery of oil in the Niger Delta began to drive the Nigerian economy and continues to dominate it today. However, the positive economic effect of oil has in turn degraded both the environment and general health. Oil spillage incidents have been increasing and occur mainly inland or in swamp and off-shore areas in the Niger Delta, South of Nigeria. ${ }^{21}$ The resulting pollution kills plants and animals, damages the environment, and destroys food chains, all of which contribute to local malnutrition and disease epidemics. Besides the oil pollution, gas flaring is also an important contributing factor to the formation 

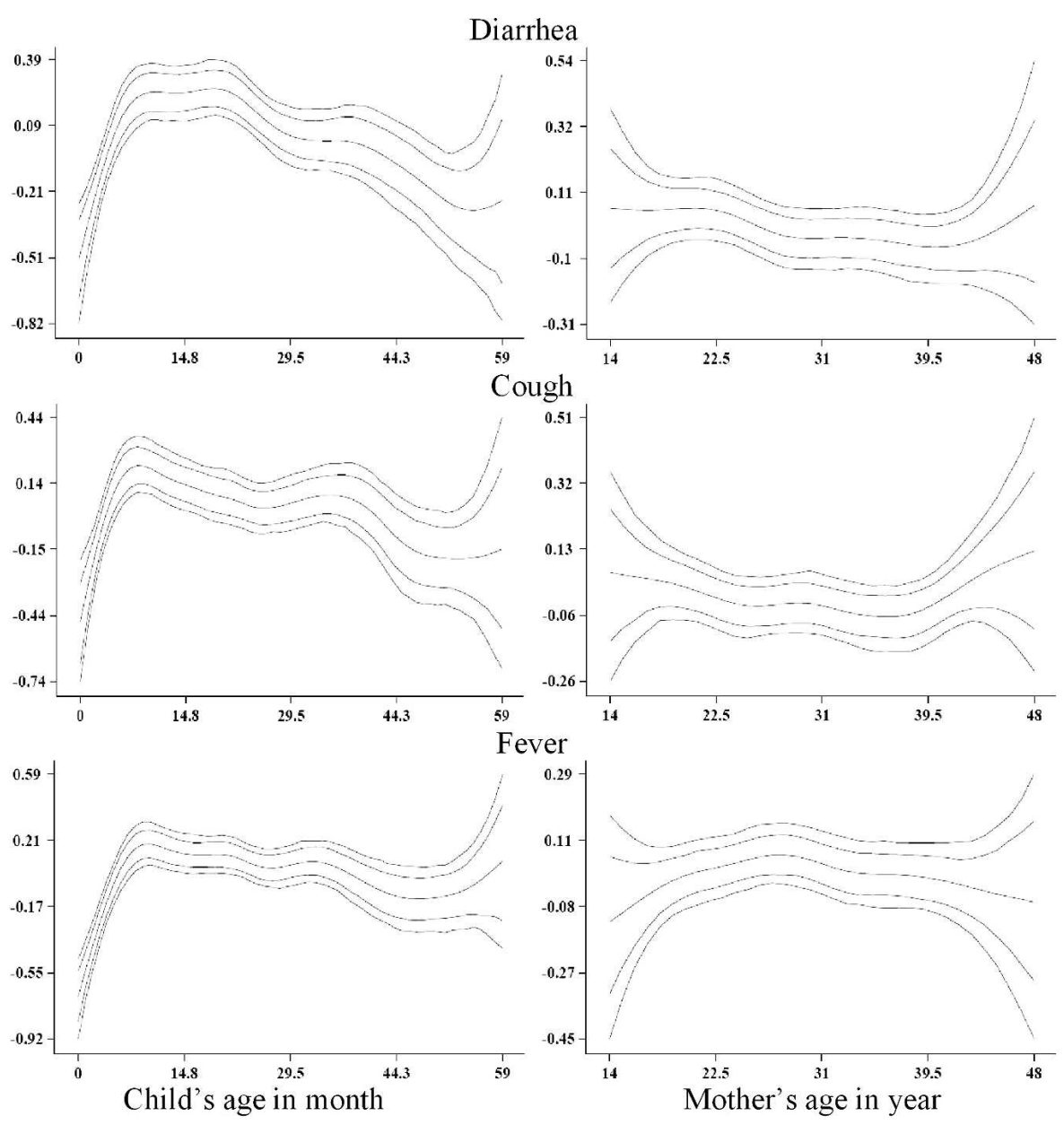

FIGURE 3. Estimated effects of child's age (in months) and mother's age (in years) on diarrhea, cough, and fever in Nigeria.

of acid rain, which is toxic to both humans and animals alike and leads to soil degradation, deforestation, and an unbalanced ecosystem. ${ }^{22}$

States with a lower association with childhood morbidity are mainly restricted to western regions. Some are found in the north and central parts of the country. As pointed out in the previous study, ${ }^{23}$ this reduced association might derive from a regional advantage prior to the discovery of oil. People in these states benefited from free education, agricultural settlements, and industrial development. ${ }^{23}$ Thus parents are still likely to have more health-care knowledge and enjoy better health conditions, which could effectively lower the associations.

Compared with our previous study on the separate analysis of each data survey, child's age shows a pronounced nonlinear effect on all 3 diseases. The rapid deterioration of the effect of a child's age and the narrow confidence intervals during the first $8-10$ months suggests that the association with childhood morbidity increases quickly and tapers off as age increases. This might be because of malnutrition in early feeding practice while a child's immune system is not sufficiently developed to protect him or her from contamination by bacteria. Because of poverty, insufficient household sanitary conditions, and other related factors, mothers might not be able to feed infants with enough clean breast milk so that mixed lowquality foods or contaminated water were used instead. For example, Ahiadeke ${ }^{24}$ found that diarrhea was prevalent in infants aged 4-6 months from households with poor sanitary conditions unless mothers reverted to exclusive breastfeeding; Woldemicael ${ }^{25}$ attributed the immediate deterioration pattern to the fact that most children were weaned during 6-12 months. It is likely that as the child's immune system develops, the associations of disease decreased, which is reflected by a gradual decline of the effect of age after 10 months in Figure 2. Another possible explanation may be that maternal immunity may be protective among young children against infectious agents that may cause each of these symptoms. The decline of maternally derived immunity since birth may account for the increase in effect in early childhood. Moreover, in this analysis the confidence intervals tended to become larger after 35 months. It should be noted, however, that this is a combined data set based on 2 surveys involving children at 2 different ages. Fewer cases were observed in the combined data set after 3 years ( 35 months), thus the fluctuation of the intervals after 35 months increases markedly.

The approximate negative linear relationship between mothers of age 20-40 years and the 3 diseases suggest that a child's association with diarrhea, cough, and fever declines as their mothers get older. However, few data from younger (age $<20$ years) and older (age $>40$ years) mothers were collected $(7.3 \%$ and $4.8 \%$ of the data, respectively). Thus, this is likely to be the explanation for the expanded $80 \%$ and $95 \%$ CIs in the graphs. 
TABLE 3

District posterior mean estimates of the fixed effect parameters for diarrhea, cough, and fever in Nigeria

\begin{tabular}{|c|c|c|c|c|c|c|c|c|c|c|c|c|}
\hline \multirow[b]{2}{*}{ Variable } & \multicolumn{4}{|c|}{ Diarrhoea } & \multicolumn{4}{|c|}{ Cough } & \multicolumn{4}{|c|}{ Fever } \\
\hline & Mean & SE & $\begin{array}{c}2.5 \% \\
\text { Quantile }\end{array}$ & $\begin{array}{c}97.5 \% \\
\text { Quantile }\end{array}$ & Mean & SE & $\begin{array}{c}2.5 \% \\
\text { Quantile }\end{array}$ & $\begin{array}{c}97.5 \% \\
\text { Quantile }\end{array}$ & Mean & SE & $\begin{array}{c}2.5 \% \\
\text { Quantile }\end{array}$ & $\begin{array}{c}97.5 \% \\
\text { Quantile }\end{array}$ \\
\hline Constant & -1.020 & 0.117 & -1.243 & -0.793 & -0.793 & 0.105 & -0.993 & -0.585 & -0.641 & 0.103 & -0.837 & -0.436 \\
\hline \multicolumn{13}{|l|}{ Mother's education } \\
\hline No education & 0 & & & & 0 & & & & 0 & & & \\
\hline Having education & $-0.126^{*}$ & 0.062 & -0.248 & -0.008 & 0.106 & 0.061 & -0.018 & 0.224 & 0.022 & 0.058 & -0.091 & 0.133 \\
\hline \multicolumn{13}{|l|}{ Partner's education } \\
\hline No education & 0 & & & & 0 & & & & 0 & & & \\
\hline Having education & 0.002 & 0.056 & -0.110 & 0.111 & -0.007 & 0.056 & -0.115 & 0.103 & 0.035 & 0.054 & -0.070 & 0.143 \\
\hline \multicolumn{13}{|l|}{ Place of residence } \\
\hline Rural & 0 & & & & 0 & & & & 0 & & & \\
\hline Urban & -0.029 & 0.053 & -0.136 & 0.079 & -0.093 & 0.053 & -0.197 & 0.007 & $-0.127 *$ & 0.047 & -0.218 & -0.034 \\
\hline \multicolumn{13}{|l|}{ Sex of child } \\
\hline Female & 0 & & & & 0 & & & & 0 & & & \\
\hline Male & 0.027 & 0.045 & -0.061 & 0.115 & 0.012 & 0.041 & -0.066 & 0.090 & 0.053 & 0.039 & -0.024 & 0.135 \\
\hline \multicolumn{13}{|l|}{ Antenatal visit } \\
\hline No visit & 0 & & & & 0 & & & & 0 & & & \\
\hline Some visits & 0.021 & 0.059 & -0.104 & 0.133 & -0.087 & 0.058 & -0.205 & 0.028 & $-0.128 *$ & 0.053 & -0.232 & -0.023 \\
\hline \multicolumn{13}{|l|}{ Type of feeding } \\
\hline No breastfeeding & 0 & & & & 0 & & & & 0 & & & \\
\hline Exclusive breastfeeding & -0.240 & 0.130 & -0.505 & 0.013 & -0.199 & 0.121 & -0.443 & 0.030 & -0.090 & 0.115 & -0.319 & 0.137 \\
\hline Mixed breastfeeding & 0.074 & 0.060 & -0.043 & 0.195 & -0.040 & 0.054 & -0.147 & 0.070 & $0.138 *$ & 0.053 & 0.033 & 0.244 \\
\hline \multicolumn{13}{|l|}{ Asset index } \\
\hline 1st quantile & 0 & & & & 0 & & & & 0 & & & \\
\hline 2nd quantile & $-0.135^{*}$ & 0.068 & -0.263 & -0.008 & 0.025 & 0.068 & -0.104 & 0.159 & 0.029 & 0.062 & -0.092 & 0.150 \\
\hline 3rd quantile & -0.119 & 0.065 & -0.240 & 0.016 & 0.090 & 0.064 & -0.031 & 0.218 & 0.001 & 0.057 & -0.112 & 0.108 \\
\hline 4th quantile & -0.082 & 0.079 & -0.228 & 0.074 & 0.078 & 0.074 & -0.060 & 0.231 & -0.016 & 0.069 & -0.155 & 0.119 \\
\hline \multicolumn{13}{|l|}{ Preceding birth interval } \\
\hline$<25$ months & 0 & & & & 0 & & & & 0 & & & \\
\hline $25+$ months & 0.063 & 0.055 & -0.045 & 0.174 & 0.044 & 0.050 & -0.057 & 0.141 & $0.096 *$ & 0.047 & 0.002 & 0.192 \\
\hline \multicolumn{13}{|l|}{ Marital status } \\
\hline Married & 0 & & & & 0 & & & & 0 & & & \\
\hline Single & 0.068 & 0.295 & -0.517 & 0.639 & -0.029 & 0.275 & -0.587 & 0.498 & -0.138 & 0.282 & -0.690 & 0.407 \\
\hline \multicolumn{13}{|l|}{ Place of delivery } \\
\hline Home and others & 0 & & & & 0 & & & & 0 & & & \\
\hline Hospital & -0.045 & 0.063 & -0.170 & 0.081 & -0.076 & 0.057 & -0.191 & 0.031 & $-0.146^{*}$ & 0.055 & -0.255 & -0.033 \\
\hline \multicolumn{13}{|l|}{ Household } \\
\hline Small size & 0 & & & & 0 & & & & 0 & & & \\
\hline Medium size & 0.025 & 0.067 & -0.110 & 0.153 & -0.023 & 0.063 & -0.141 & 0.096 & 0.030 & 0.059 & -0.083 & 0.143 \\
\hline Large size & 0.018 & 0.073 & -0.129 & 0.163 & 0.074 & 0.071 & -0.058 & 0.220 & 0.053 & 0.066 & -0.077 & 0.184 \\
\hline
\end{tabular}

In line with the results from the 2003 survey, children of educated mothers had a lower association with diarrhea. This finding suggests that these mothers were likely to have more health-care knowledge to protect their children and to deal with these conditions more effectively. The World Bank and the 2003 NDHS reports both found that mother's education can significantly reduce childhood morbidity by improving the mother's health seeking ability.

In a previous study, ${ }^{6}$ only children from families of the second-lowest economic status had a significantly lower association with diarrhea than those from other families, while other SES categories showed no significant association with childhood diarrhea. It is important to point out that in this analysis the calculation of asset index was based on questions of ownership of several household items, such as a car, bicycle, radio, and telephone. It is possible that these items might be more common in urban areas than rural ones in SSA countries. ${ }^{26}$ As such, asset index classification may not represent the real economic structure of the households in Nigeria.

We also found several factors with significant effects on childhood fever. Table 3 shows that children whose mothers had had prenatal visits and delivered in hospitals experienced a significantly reduced association with childhood fever. It is likely that hospitals provided mothers with prenatal advice and administered professional health care to the infants. In addition to the mother-related factors, urban children had a significantly lower association than rural children across the country. Recent research ${ }^{27}$ showed that urban children were twice as likely to be immunized and have access to basic health-care services as rural children, which gives a reasonable explanation for this result. Children fed mixed foods (mixed breastfeeding) had the highest association with childhood fever among the 3 types of feeding practices. Mixed breastfeeding may cause infant malnutrition and increase the risks from infectious diseases. Some studies ${ }^{24,28,29}$ found evidence that mixed feeding is related to infant mortality. The high risk of fever was also found in children who were born at least 2 years after their previous siblings (preceding birth interval $>24$ months). Several researchers found contradictory results showing childhood diarrhea decreases as birth interval increases. ${ }^{30,31}$ However, different data sources and time period might be the main reasons resulting in this difference.

In this report, $\approx 50 \%$ of the factors in the preliminary analysis showed a significant association with the 3 diseases $(P<$ 
0.01 ), while only $7 \%$ showed such an association with only 2 conditions (diarrhea and fever) in the multivariate analysis. A possible explanation for this is that health-care utilization reflects the accessibility of health-care services and has been captured by the spatial effects in the multivariate analysis. ${ }^{26}$

We identified an east-west spatial pattern for childhood diarrhea, cough, and fever by mapping the posterior mean results of the model. In addition, the highly nonlinear effect of child's age has emerged, which is difficult to assess with conventional parametric models. Our study indicates that policy makers should specifically address the increasing health issues among children under 8-10 months. More emphasis should be given to the WHO guidelines on exclusive breastfeeding for 6 months after birth, as we found that children who are solely breastfed are at a lower association with infection. In addition, mother's education, place of residence, prenatal visits, asset index, preceding birth interval, and place of delivery were also significantly associated with child morbidity.

It is worth mentioning some advantages of our approach over existing ones using, for example, logistic models with constant-fixed effects of covariates and fixed (or random) districts (states) effects or standard two-level multilevel modeling with unstructured spatial effects (see Appendix at www .ajtmh.org). With standard models, it is assumed that the random components at the contextual level (district or state) are mutually independent, even though, in practice, this assumption is not actually implied by these approaches, so correlated random residuals could also be specified. ${ }^{7}$ The independence assumption has an inherent problem of inconsistency: if the location of the event matters, then it makes sense to assume that areas close to each other are more similar than areas that are far apart. Also, the NDHS data are based on a random sample of districts or states. That is, the structured component introduced here allows us to "borrow strength" from neighbors to cope with the sample variation of the district or state effect and obtain estimates for areas that may have inadequate sample sizes or be unsampled. In the exploratory analysis, we tried several models to highlight the differences that can be found by adopting this approach in a spatial context and the possible bias involved with the violation of the independent assumption between aggregated spatial areas. Our final model has a spatial component and a random component that reflect spatial heterogeneity globally and relative homogeneity among neighboring states [see Model (2)], while the other model did not [see Model (1)]. Failure to take into account the posterior uncertainty in the spatial location (district or state) would overestimate the precision of the association of childhood morbidity in unsampled districts.

\section{POLICY IMPLICATION}

The study findings have some important and relevant policy messages. Child's age effect suggests the need to pay attention to child feeding practices, particularly during the first 6 months after birth. More emphasis should also be given to the WHO guidelines on exclusive breastfeeding for 6 months after birth, as we found that children that are solely breastfed are at a lower risk of infection. Of high significance is the influence of the community (district) where the children live on childhood diseases. This suggests that children in the northeast of Nigeria and children living in rural areas have a higher association with childhood diseases compared with other children. Policy makers should place more emphasis on the role of remoteness as well as environmental or climatic factors on childhood diseases. Our maps could be used by policy makers for targeting development efforts at a glance for health-care intervention to achieve the Millennium Development Goals in Sub-Saharan Africa.

Received February 25, 2007. Accepted for publication June 13, 2007.

Acknowledgments: The authors thank participants at seminars in Warwick and at the BIOMETRIC Conference in Montreal and the British Population Conference in Southampton for helpful comments and discussions. We also thank Macro Int. for providing free data sets for Nigeria.

Financial support: This work is supported by the UK Economic \& Social Research Council (ESRC, grant no. RES-000-22-1221).

Contributions: N.-B. Kandala—conception and design; literature review; data analysis and interpretation; drafting the article; approval of final article for submission. C. Ji-literature review; data analysis and interpretation; drafting the article. N. Stallard-interpretation of results; critical revisions for important intellectual content; approval of final article for submission. S. Stranges-interpretation of results; critical revisions for important intellectual content. F.P. Cappucciointerpretation of results; critical revisions for important intellectual content; approval of final article for submission.

Authors' addresses: Ngianga-Bakwin Kandala, Chen Ji, Saverio Stranges, and Francesco P. Cappuccio, Clinical Sciences Research Institute, Warwick Medical School, Coventry CV2 2DX, U.K., Telephone: +44 (0)24 76968669, Fax: +44 (0)24 76968660, E-mail: N-B.Kandala@warwick.ac.uk. Nigel Stallard, Health Sciences Research Institute, Warwick Medical School, Coventry CV4 7AL, U.K.

Reprint requests: Ngianga-Bakwin Kandala, Clinical Sciences Research Institute, Warwick Medical School, University of Warwick, Clifford Bridge Road, Coventry CV2 2DX, U.K., Telephone: +44 (0)24 76968669, Fax: +44 (0)24 76968660, E-mail: N-B.Kandala@ warwick.ac.uk.

\section{REFERENCES}

1. Oyedeji GA, Olamijulo SK, Osinaike AI, Esimai VC, Odunusi EO, Aladekomo TA, 1995. Anthropometric measurement in children aged 0-6 years in a Nigerian village. East Afr Med J 72: 523-526.

2. Adebayo SB, Fahrmeir L, 2005. Analysing child mortality in Nigeria with geoadditive discrete-time survival models. Stat Med 24: 709-728.

3. Vaahtera M, Kulmala T, Maleta K, Cullinan T, Salin M-L, Ashorn P, 2000. Epidemiology and predictors of infant morbidity in rural Malawi. Paediatr Perinat Epidemiol 14: 363-371.

4. Lindskog U, Lindskog P, Gebre-Medhin M, 1987. Child health and household water supply: a longitudinal study of growth and its environmental determinants in rural Malawi. Hum Nutr Clin Nutr 41: 409-423.

5. Yoannes AG, Streatfield K, Bost L, 1992. Child morbidity patterns in Ethiopia. J Biosoc Sci 24: 143-155.

6. Kandala N-B, 2006. Bayesian geo-additive modelling of childhood morbidity in Malawi. Appl Stochast Models Bus Ind 22: 139-154.

7. Fahrmeir L, Lang S, 2001. Bayesian inference for generalized additive mixed models based on Markov random field priors. Appl Stat 50: 201-220.

8. Filmer D, Pritchett L, 2001. Estimating wealth effects without expenditure data-or tears: an application to educational enrollments in states of India. Demography 38: 115-132.

9. Isabella S, Ziyane RN, 1999. The relationship between infant feeding practices and diarrhoeal infections. J Adv Nurs 29: 721-726.

10. Fahrmeir L, Kneib T, Lang S, 2004. Penalized structured additive regression for space-time data: a Bayesian perspective. Stat Sinica 14: 731-761.

11. Kandala N-B, Madise NJ, 2004. Spatial epidemiology of child- 
hood diseases in Malawi and Zambia. Afr Popul Stud 19 (Suppl B): 199-226.

12. Kammann EE, Wand MP, 2003. Geoadditive models. J R Stat Soc C 52: 1-18.

13. Goldstein H, 1999. Multilevel Statistical Models. First internet edition. London: Arnold. Available at: http://www.ats.ucla .edu/stat/examples. Accessed January 24, 2007.

14. Lang S, Brezger A, 2004. Bayesian P-splines. J Comput Graph Stat 13: 183-212.

15. Eilers PHC, Marx BD, 1996. Flexible smoothing with B-splines and penalties (with discussion). Stat Sci 89: 89-121.

16. Besag J, York Y, Mollie A, 1991. Bayesian image restoration with two applications in spatial statistics. Annu Inst Stat Math 43: 1-59.

17. Spiegelhalter D, Best N, Carlin B, Van der Line A, 2002. Bayesian measures of models complexity and fit. J R Stat Soc Ser B 64: $1-34$.

18. Kandala N-B, Ghilagaber G, 2006. A geo-additive Bayesian discrete-time survival model and its application to spatial analysis of childhood mortality in Malawi. Qual Quant: Int J Methodol 40: 935-957.

19. Adefolalu DO, 1986. Further aspects of Sahelian drought as evident from rainfall regime of Nigeria. Meteorol Atmospher Phys 36: $277-295$

20. Aall C, Helsing E, 1976. The Sahelian drought II. J Trop Pediatr Environ Child Health 22: 69-93.

21. Nwilo PC, Badejo OT, 2006. Impacts and management of oil spill pollution along the Nigerian coastal areas. Administering Marine Spaces: International Issues. FIG Publication No. 36. Fredriksberg, Denmark: The International Federation of Surveyors (FIG). ISBN: 87-90907-55-8. Available at: http:// www.fig.net/pub/figpub/pub36/chapters/chapter_8.pdf. Accessed December 8, 2006.

22. Energy Information Administration, 2003. Nigeria: Environmen- tal Issues. Available at: http://www.eia.doe.gov/emeu/cabs/ nigenv.html. Accessed November 1, 2006.

23. United Nations Development Programme, 2006. Niger Delta Human Development Report. Available at: http://hdr.undp.org/ reports/detail_reports.cfm?view $=1060$. Accessed November $1,2006$.

24. Ahiadeke C, 2000. Breast-feeding, diarrhoea and sanitation as components of infant and child health: a study of large scale survey data from Ghana and Nigeria. J Biosoc Sci 32: 47-61.

25. Woldermicael G, 2001. Diarrhoeal morbidity among young children in Eritrea: environmental and socioeconomic determinants. J Health Popul Nutr 19: 83-90.

26. Kandala N-B, Magadi MA, Madise NJ, 2006. An investigation of district spatial variations of childhood diarrhoea and fever morbidity in Malawi. Soc Sci Med 62: 1138-1152.

27. POLICY Project/Nigeria, 2002. Child Survival in Nigeria: Situation, Response and Prospects-Key Issues. Available at: http:// www.policyproject.com/pubs/countryreports/NIG_CS.pdf. Accessed November 1, 2006.

28. Guay LA, Ruff AJ, 2001. HIV and infant feeding-an ongoing challenge. JAMA 286: 2462-2464.

29. Latham MC, Preble EA, 2000. Appropriate feeding methods for infants of HIV infected mothers in sub-Saharan Africa. BMJ 320: $1656-1660$.

30. Rutstein SO, 2005. Effects of preceding birth intervals on neonatal, infant and under-five years mortality and nutritional status in developing countries: evidence from the demographic and health surveys. Int J Gynecol Obstet 89 (Suppl 1): S7-S24.

31. WHO/AFRO, 2004. Africa's Neonatal Morbidity and Mortality Rates Are among the Highest in the World. Brazzaville, Congo: World Health Organization, Regional Office for Africa. Available at: http://www.afro.who.int/press/2004/pr20040218.html Accessed December 13, 2006. 


\section{APPENDIX}

\section{STATISTICAL METHODS}

Epidemiological investigations of spatial variations of diseases are often confined to using region-specific dummy variables to capture the spatial dimension. In this analysis, we propose a novel approach by exploring regional patterns of childhood morbidity and possible nonlinear effects of other factors within a simultaneous, coherent regression framework using a geoadditive semiparametric mixed model. As the predictor contains usual linear terms, nonlinear effects of metrical covariates, and geographic effects in an additive form, such models are also called geoadditive models. Kammann ${ }^{8}$ proposed this type of models within an empirical Bayesian approach. Here, we apply a fully Bayesian approach as suggested in Fahrmeir and Lang, ${ }^{7}$ which is based on Markov priors and uses Markov chain Monte Carlo (MCMC) techniques for inference and model checking.

Consider regression situations, where observations $\left(y_{i} ; x_{i}\right.$; $\left.w_{i}\right) ; i=1, \ldots, N$, on a binary response $y$, a vector $\mathbf{x}=\left(\mathbf{x}_{i} ; \ldots ;\right.$ $\left.\mathbf{x}_{\mathrm{p}}\right)^{\prime}$ of metrical covariates (child's age), time scales or spatial covariates (districts), and a vector $\mathbf{w}=\left(\mathbf{w}_{1} ; \ldots ; \mathbf{w}_{\mathrm{r}}\right)^{\prime}$ of further covariates, in which categorical covariates are often given. The generalized additive modeling framework assumes that, given $x_{i}$ and $w_{i}$, the distribution of the response $y_{i}$ belongs to an exponential family, with mean $\mu_{i}=\mathrm{E}\left(y_{i} \mid-\mathrm{x}_{i}, w_{i}\right)$ linked to an additive semiparametric predictor $\mu_{\mathrm{I}}=h(\eta)$.

Traditionally, the effect of the covariates on the response is modeled by a linear predictor

$$
\eta_{i}=x_{i}^{\prime} \beta+w_{i}^{\prime} \gamma
$$

where $h$ is a known response function. The response variable in this application is defined as $Y_{i}=1$ if child $i$ had diarrhea, cough, fever during the reference period $t$ and $Y_{i}=0$ otherwise. We have a probit link function $\operatorname{Pr}\left(y_{i}=1 \mid x_{i}{ }^{*}\right)=\Phi\left(\eta_{i}\right)$ for the probability of having diarrhea, cough, fever at the reference period (i.e., we model the conditional probability of a child having diarrhea, cough, fever) given the child's age in months, the district where the child lives, and $X$, with predictor (A1).

In our application to childhood morbidity and in many other regression situations, we are facing the following problems:

- For the continuous covariates in the data set, the assumption of a strictly linear effect on the response $y$ may not be appropriate. In our study, such covariates are child's age (age) and mother's age at birth of the child (mab). Generally, it will be difficult to model the possibly nonlinear effect of such covariates through a parametric functional form, which has to be linear in the parameters, prior to any data analysis.

- In addition to usual covariates, geographical small-area information is given in the form of a location variable $s$, indicating the region, district or community where individuals or units in the sample size live or come from. In our study, this geographical information is given by the states or districts where the child lives at the time of the survey. Attempts to include such small-area information using district-specific dummy variables would in our case entail $>50$ dummy variables and could not access spatial interdependence. The latter problem could not be solved through conventional multilevel modeling using uncorrelated random effects. ${ }^{10}$ It is reasonable to assume that areas close to each other are more similar than areas far apart, so that spatially correlated random effects are required.

To overcome these difficulties, we replace the strictly linear predictor through a geoadditive predictor, leading to the geoadditive regression model:

$$
\eta_{i}=f_{1}\left(x_{i 1}\right)+\ldots+f_{\mathrm{p}}\left(x_{i \mathrm{p}}\right)+f_{\text {spat }}\left(s_{i}\right)+w_{i}^{\prime} \gamma
$$

here, $f_{1}, \ldots, f_{\mathrm{p}}$ are nonlinear smooth effects of the metrical covariates, and $f_{\text {spat }}\left(s_{i}\right)$ is the effect of the spatial covariate $s_{i} \in\{1, \ldots, S\}$ labeling the districts in Nigeria. Regression models with predictors as in (A2) are sometimes referred to as geoadditive models.

In a Bayesian approach, unknown functions $f_{j}$ and parameters $\gamma$ as well as the variance parameter $\sigma^{2}$ are considered as random variables and have to be supplemented with appropriate prior assumptions. In the absence of any prior knowledge, we assume independent diffuse priors $\gamma_{j} \propto$ const, $j=$ $1, \ldots, r$ for the parameters of fixed effects. Another common choice is highly dispersed Gaussian priors.

Several alternatives are available as smoothness priors for the unknown functions $f_{j}\left(x_{j}\right)$, see References 6,7 , and 10 . We use Bayesian penalized splines (P-splines), ${ }^{14}$ introduced by Eilers and Marx $^{13}$ in a frequentist setting. For the spatially correlated effect $f_{\text {str }}(s), s=1, S$, we choose Markov random field prior parameters common in spatial statistics. $6,7,10,11,14,18$ These priors reflect spatial neighborhood relationships. For geographical data, one usually assumes that 2 sites or regions $s$ and $r$ are neighbors if they share a common boundary. Then a spatial extension of random walk models leads to the conditional, spatially autoregressive specification

$$
f_{\text {str }}(s) \mid f_{\text {str }}(r), r \neq s \sim N\left(\sum_{r \in \partial_{X}} f_{\text {str }}(r) / N_{s}, \tau^{2} / N_{s}\right),
$$

where $N_{s}$ are the number of adjacent regions, and $r \in \partial_{\mathrm{s}}$ denotes that region $r$ is a neighbor of region $s$. Thus the (conditional) mean of $f_{\text {str }}(s)$ is an average of function evaluations $f_{\text {str }}(s)$ of neighboring regions. Again, the variance $\tau^{2}$ str controls the degree of smoothness.

For a spatially uncorrelated (unstructured) effect $f_{\text {unstr }}$, a common assumption is that the parameters $f_{\text {unstr }}(s)$ are independently and identically distributed Gaussian

$$
f_{\text {unstr }}(s) \mid \tau_{\text {unstr }}^{2} \sim N\left(0, \tau_{\text {unstr }}^{2}\right) .
$$

The standard measure of effect is still the OR for a logistic model and mean for a probit model. However, because of the use of a fully Bayesian approach that relies on prior assumption to make posterior inference, instead of "OR" or mean, we have "posterior OR" or posterior mean. For model choice, we routinely use the deviance information criterion (DIC) ${ }^{17}$ developed as a measure of fit and model complexity instead of tests for significance, linear trends, and interactions. To account for possible departures from the assumed distribution, 95\% confidence intervals (CIs) for the posterior ORs and probability maps (the equivalent of CIs for the spatial effects) are calculated using robust standard errors estimated via MCMC simulation techniques. 